УДК 615.322:547.913(571)

\title{
ИССЛЕДОВАНИЕ МАСЛА БРУСНИКИ, ПОЛУЧАЕМОГО ЭКСТРАКЦИЕЙ СВЕРХКРИТИЧЕСКИМ ДИОКСИДОМ УГЛЕРОДА
}

\author{
() А.Д. Ивахнов ${ }^{1 *}$, Т.Э. Скребец ${ }^{1}$, М.В. Богданов ${ }^{1}$, К.Г. Боголицын ${ }^{1,2}$, Е.Д. Тремзина \\ ${ }^{1}$ Северный (Арктический) фредеральный университет имени М.В. \\ Ломоносова, наб. Северной Двины, 17, Архангельск, 163002 (Россия), e-mail: \\ ivahnov-tema@yandex.ru \\ ${ }^{2}$ Институт экологических проблем Севера УрО РАН, Архангельск, \\ наб. Северной Двины, 23, 163002 (Россия) \\ ${ }^{3} \mathrm{OАО}$ «Архангельский ликеро-водочный завод», Архангельск, наб. Северной \\ Двины, 120, 163001 (Россия)
}

Выполнены сопоставительные исследования способов выделения масла из ягод брусники (Vaccínium vítis-idaéa) с применением в качестве растворителей гексана и сверхкритического диоксида углерода. Определены основные показатели качества получаемого масла и его жирнокислотный состав. Показано, что сверхкритический диоксид углерода может быть использован для выделения брусничного масла вместо традиционно используемых для этих целей углеводородов.

Ключевые слова: масло, брусника, сверхкритическая флюидная экстракция, диоксид углерода, состав.

Работа выполнена при финансовой поддержке Министерства образования и науки РФ, ГК от 23 мая 2011 г. № 14.740.11.1019, и гранта РФФИ №11-03-12021-офи-м-2011.

\section{Введение}

Брусника представляет собой небольшой вечнозеленый кустарник семейства вересковых, образующий красные съедобные плоды. Она редко культивируется, плоды, как правило, собирают с дикорастущих

Ивахнов Артём Дмитриевич - научный сотрудник центра коллективного пользования научным оборудованием «Арктика», кандидат химических наук, тел.: (8182) 21-89-48, e-mail: ivahnov-tema@yandex.ru Скребеи Татьяна Эдуардовна - профессор кафедры теоретической и прикладной химии, кандидат химических наук, тел.: (8182) 21-89-48,

e-mail: t.skrebets@agtu.ru

Богданов Михаил Владиславович - доцент кафедры теоретической и прикладной химии, кандидат химических наук, тел.: (8182) 21-89-48

Боголииын Константин Григорьевич - проректор по научной работе Северного (Арктического) федерального университета им. М.В. Ломоносова, директор Института экологических проблем Севера УрО РАН, заведующий кафедрой теоретической и прикладной химии, доктор химических наук, профессор, тел.: (8182) 28-76-36,

e-mail: bogolitsyn@agtu.ru

Тремзина Елена Дмитриевна - директор по производству и качеству кустов. Средой обитания являются циркумбореальные леса Северной Евразии и Северной Америки.

Ягоды брусники являются ценным пищевым сырьем. Одним из его потребителей является ликероводочная промышленность. Основным отходом при приготовлении настоек на основе брусники является жмых (шрот) ягод, содержащий некоторое количество спирта и воды, а также многие компоненты, не извлекаемые при экстракции 45\%-м раствором этилового спирта. Одним из направлений повышения рентабельности производства и снижения оказываемой им экологической нагрузки может являться переработка шрота с целью получения ценных продуктов.

В литературе не проявлен интерес к переработке ягод брусники с целью получения масел и других компонентов. Большинство работ посвящены переработке брусничного листа [1].

\footnotetext{
* Автор, с которым следует вести переписку.
} 
Существует два основных способа получения масел из масличного сырья: экстракция и отжим (холодный или горячий). Механический отжим масла связан с большими техническими трудностями, что приводит к его вытеснению экстракционным способом. Вместе с тем последний обладает значительными недостатками, связанными прежде всего с применением токсичных углеводородных растворителей.

Реальной альтернативой существующему способу может стать сверхкритическая флюидная экстракция [2-8].

Ввиду уникальных свойств (низкие значения критических параметров - $\mathrm{T}_{\text {кр }} 304 \mathrm{~K}, \mathrm{P}_{\text {кр }} 7,4$ МПа, негорючесть и нетоксичность, хорошая растворяющая способность по отношению ко многим веществам) диоксид углерода является одним из основных растворителей, применяемых при реализации сверхкритических флюидных технологий.

Цель данной работы - изучение возможности выделения масла из послеэкстракционного жмыха ягод брусники с использованием в качестве растворителя сверхкритического диоксида углерода.

\section{Объект и методы исследования}

В качестве объекта исследования был выбран жмых брусники, проэкстрагированный 45\%-м этиловым спиртом на ОАО «Архангельский ликеро-водочный завод». Жмых предварительно был высушен при температуре $105^{\circ} \mathrm{C}$ до остаточной влажности $2 \%$. Исходное сырье было заготовлено в Архангельской области в 2012 г.

Для определения жирнокислотного состава полученных масел использован метод газожидкостной хроматографии по ГОСТ 30418-96 с предварительным щелочным гидролизом и получением метиловых эфиров жирных кислот [9].

В виалу отбирали 0,1 мл масла, добавляли 1 мл гексан-эфирной смеси $1: 1$, затем вносили 0,5 мл 2 М КОН в метаноле, содержимое виалы интенсивно встряхивали в течение 2 мин. После пятиминутного отстаивания отбирали верхний слой для газохроматографического анализа.

Количественное определение метиловых эфиров жирных кислот проводили, используя хроматограф Agilent Technologies 7820A GC System Maestro: колонка капиллярная: ZB-FFAP, $50 \mathrm{~m} \times 0,32 \mathrm{~mm} \times 0,50 \mu \mathrm{m}$, газ-носитель - азот, детектор пламенно-ионизационный.

Определение содержания хлорофилла выполнено методом спектрометрии в видимой области спектра с использованием спектрофотометра Specord 250 Plus. Расчет проведен относительно $а$ хлорофилла $(\varepsilon=91,2, \lambda=662$ нм $)[10]$.

\section{Результаты и обсуждение}

Определение массовой доли масел проводили по стандартной методике [9], основанной на экстракции сырья гексаном в аппарате Сокслета и последующей отгонке растворителя в вакууме. Полученный образец использован в качестве образца сравнения.

Сверхкритическая флюидная экстракция выполнена с использованием установки SFE 5000 производства Waters Corporation. Навеску сырья (79 г) помещали в автоклав объемом 200 мл и обрабатывали диоксидом углерода при температуре $70{ }^{\circ} \mathrm{C}$, давлении 500 атм и при скорости потока 15 г/мин. Расход диоксида углерода составлял 50 кг/кг сырья. Высокий удельный расход диоксида углерода может быть компенсирован организацией его рецикла.

Определение физических (плотность, показатель преломления) и химических (кислотное, йодное, эфирное число, число омыления, перекисное число, содержание серы) показателей проводили по стандартным методикам [10].

Ягоды брусники могут содержать до 4\% масла, которое преимущественно сконцентрировано в семенах. Сырое масло может содержать различные растворенные компоненты (хлорофиллы, каротиноиды, гормоны) [11]. Классическим методом (экстракция гексаном) было установлено содержание масла 3,2\% в сухих ягодах. Методом сверхкритической флюидной экстракции $\left(\mathrm{CКФЭ-} \mathrm{CO}_{2}\right)$ с применением в качестве растворителя диоксида углерода было получено масло с выходом $3 \%$.

Физико-химические и органолептические показатели полученных масел приведены в таблице 1 . По величине параметров плотность и показатель преломления оба образца практически идентичны. Отсутствие запаха у образца, полученного экстракцией гексаном, закономерно, ввиду того что экстракт был упарен под вакуумом при удалении растворителя. Отсутствие запаха у масла, полученного сверхкритической флюидной экстракцией, объясняется одновременной его дезодорацией. 
Таблица 1. Органолептические и физико-химические показатели брусничного масла

\begin{tabular}{|c|c|c|}
\hline \multirow{2}{*}{ Наименование показателя } & \multicolumn{2}{|c|}{ Характеристика масла } \\
\hline & Экстракция гексаном & Экстракция диоксидом углерода \\
\hline Прозрачность & \multicolumn{2}{|c|}{ Непрозрачно } \\
\hline Консистенция & \multicolumn{2}{|c|}{ Твердая паста } \\
\hline Цвет & Зеленовато-желтый & Желтый с зеленоватым оттенком \\
\hline Запах & \multicolumn{2}{|c|}{ Отсутствует } \\
\hline Вкус & \multicolumn{2}{|c|}{ Приятный, не горький } \\
\hline Плотность, г/дм ${ }^{3}$ & 919 & 919 \\
\hline Показатель преломления & 1,474 & 1,475 \\
\hline Кислотное число, мг $\mathrm{NaOH} / \Gamma$ & 4,6 & 1,5 \\
\hline Число омыления, мг NaOH/г & 192 & 196 \\
\hline Эфирное число, мг NaOH/г & 187,4 & 194,5 \\
\hline Йодное число г $\mathrm{I}_{2} / 100$ г & 162 & 171 \\
\hline Перекисное число, $1 / 2 \mathrm{O}$ ммоль/кг & 1,62 & 0,42 \\
\hline Влага и летучие вещества, \% & 0,2 & 0,2 \\
\hline Содержание хлорофилла, г/100 г & 0,2 & 0,4 \\
\hline
\end{tabular}

Полученное методом сверхкритической флюидной экстракции брусничное масло характеризуется значительно более низким кислотным числом, что указывает на меньшее содержание в нем свободных жирных кислот и более полное извлечение жирных кислот, связанных в триглицериды, о чем также свидетельствует повышенное эфирное число. Повышенное значение числа омыления масла, полученного методом СКФЭ, также объясняется более высокой растворимостью эфиров алифатических кислот по сравнению с растворимостью соответствующих кислот [12].

Различие йодных чисел в 9 г $\mathrm{I}_{2} / 100$ г масла указывает на большую долю ненасыщенных жирных кислот в составе масла, полученного методом СКФЭ. Низкая величина перекисного числа в масле, получаемом экстракцией с помощью сверхкритического $\mathrm{CO}_{2}$, вполне закономерна. Технология экстракции исключает контакт нагретого сырья или выделенного масла с кислородом окружающей среды. При экстракции с помощью аппарата Сокслета данное взаимодействие имеет место, что и приводит к увеличению перекисного числа до $1,62 \frac{1}{2} 2$ ммоль/кг. Влажность и летучесть двух образцов масел оказалась на одинаковом уровне. Масло, получаемое методом сверхкритической флюидной экстракции, несколько обогащено хлорофиллом, что является положительным фактором при использовании его в пищевом производстве.

Жирнокислотный состав полученных масел (табл. 2) близок, однако масло, полученное методом СКФЭ- $\mathrm{CO}_{2}$, характеризуется значительно более низким содержанием сквалена и токоферолов, а также несколько повышенным содержанием линолевой кислоты, являющейся $\omega-2$ непредельной жирной кислотой, ценной с диетической точки зрения.

Таблица 2. Жирнокислотный состав рапсового масла

\begin{tabular}{l|c|c}
\hline \multirow{2}{*}{ Наименование показателей } & \multicolumn{2}{|c}{ Характеристика рапсового масла } \\
\cline { 2 - 3 } \multicolumn{1}{c|}{1} & Экстракция гексаном & Экстракция диоксидом углерода \\
\hline \multicolumn{2}{c}{ Жирные кислоты, \% } \\
\hline 12-метилтридекановая (13:1) & 0,1 & 0,1 \\
Пентадекановая (15:0) & 0,01 & 0,01 \\
Пальмитолеиновая (16:1) & 0,07 & 0,6 \\
Пальмитиновая (16:0) & 9 & 6,04 \\
2-гексилциклопентановая & 0,05 & 0,02 \\
Гептодекановая (17:1) & 0,02 & 72 \\
Линолевая (18:2) & 70 & 13 \\
Олеиновая (18:1) & 13 & 6 \\
Линоленовая (18:3) & 6 & 0,2 \\
Эйкозадиеновая (20:2) & 0,2 & 0,1 \\
Эйкозеновая (20:1) & 0,3 & 0,1 \\
Эйкозановая (20:0) & 0,1 & 0,1 \\
Не идентифицирована & 0,1 & 0,1 \\
Докозановая (22:0) & 0,1 & 0,01 \\
Трикозановая (23:0) & 0,01 & 0,03 \\
Тетракозановая (24:0) & 0,04 & 0,02 \\
Гексакозановая (26:0) & 0,03 & \\
\hline
\end{tabular}


Окончание таблищы 2

\begin{tabular}{l|c|c}
\hline \multicolumn{1}{c|}{$l$} & 2 & 3 \\
\hline \multicolumn{3}{c}{ Некислотные компоненты, \% } \\
\hline Сквален & 0,02 & 0,005 \\
Токоферолы & 0,02 & 0,01 \\
$\beta$-ситостерин & 1,1 & 1,0 \\
\hline
\end{tabular}

Брусника используется в народной медицине для лечения воспалительных и гнойных заболеваний. Уникальный состав масла, извлеченного из этого арктического вида ягод, прекрасно отвечает потребностям человеческой кожи. Протекторными свойствами обладают ненасыщенные жирные кислоты, входящие в состав липидов. Среди прочих масло брусники содержит линолевую и линоленовую кислоты, особенно ценные для диеты. Линолевая кислота является необходимым компонентам при синтезе керамидов, ключевой группы соединений, входящих в состав липидного барьера кожи. Они также ингибируют УФиндуцированую гиперпигментацию, обладают противовоспалительными свойствами. Масло семян брусники имеет высокое содержание линоленовой кислоты [13].

\section{Вblводbl}

1. Показана возможность извлечения масла из высушенных и проэкстрагированных этиловым спиртом ягод брусники методом сверхкритической флюидной экстракции с использованием в качестве растворителя сверхкритического диоксида углерода.

2. Предложенный подход может быть использован для переработки шрота ликероводочных предприятий.

3. Основное отличие масла, полученного методом СКФЭ- $\mathrm{CO}_{2}$, от масла, получаемого экстракцией гексаном, состоит в повышенной доле триглицерида при уменьшении доли свободных кислот.

Экспериментальная часть работы выполнена на оборудовании ЦКП НО «Арктика» (Северный (Арктический) федеральный университет имени М.В. Ломоносова) при финансовой поддержке Минобрнауки России».

\section{Список литературы}

1. Группа компаний ГОРО. Сверхкритическая флюидная экстракция. [Электронный pecypc]. URL: http://www.extract.ru/

2. Thobani M., Diosady L.L. Two-phase solvent extraction of canola // Journal American Oil Chemist's Society. 1997. Vol. 70. Pp. 207-214.

3. Illés V., Daood H.G., Perneczki L.S., Szokonya L., Then M. Extraction of coriander seed oil by CO2 and propane at super- and subcritical conditions // The Journal of Supercritical Fluids. 2000. Vol. 17. Pp. 177-186.

4. Hegel P.E., Zabaloy M.S., Mabe G.D.B., Pereda S., Brignole E.A. Phase equilibrium engineering of the extraction of oils from seeds using carbon dioxide + propane solvent mixtures // The Journal of Supercritical Fluids. 2007. Vol. 42. Pp. 318-324.

5. Hamdan S., Daood H.G., Toth-Markus M., Illés V. Extraction of cardamom oil by supercritical carbon dioxide and sub-critical propane // The Journal of Supercritical Fluids. 2008. Vol. 44. Pp. 25-30.

6. Freitas L.S., Oliveira J.V., Dariva C., Jacques R.A., Caramão E.B. Extraction of grape seed oil using compressed carbon dioxide and propane: extraction yields and characterization of free glycerol compounds // Journal of Agricultural and Food Chemistry. 2008. Vol. 56. Pp. 2558-2564.

7. Corso M.P., Fagundes-Klein M.R., Silva E.A., Cardozo-Filho L., Santos J.N., Freitas L.S., Dariva C. Extraction of sesame seed (Sesamun indicum L.) oil using compressed propane and supercritical carbon dioxide // The Journal of Supercritical Fluids. 2010. Vol. 52. Pp. 56-61.

8. Boutin O., Badens E. Extraction from oleaginous seeds using supercritical $\mathrm{CO}_{2}$ : experimental design and products quality // Journal of Food Engineering. 2009. Vol. 92. Pp. 396-402.

9. Артюнян Н.С., Корнена Е.П., Мартовщук Е.В. Лабораторный практикум по химии жиров. СПб., 2004. 264 с.

10. ГОСТ 13496.15-97. Корма, комбикорма, комбикормовое сырье. Методы определения содержания сырого жира.

11. ГОСТ 30418-96. Масла растительные. Метод определения жирнокислотного состава.

12. Gupta Ram B., Jae-Jin Shim. Solubility in supercritical carbon dioxide. New York, 2007. 909 p.

13. Тютюнников Б.Н. Химия жиров. М., 1974. 260 с. 
Ivahnov A.D. ${ }^{*}$, Skrebets T.E. ${ }^{l}$, Bogdanov M.V. ${ }^{1}$, Bogolitsyn K.G. ${ }^{1,2}$, Tremzina E.D. ${ }^{3}$ THE STUDY OF COWBERRY OIL PRODUCED BY EXTRACTION WITH SUPERCRITICAL CARBON DIOXIDE

${ }^{I}$ Northern (Arctic) Federal University named after M.V. Lomonosov, Northern Dvina Emb., 17, Arkhangelsk, 163002

(Russia), e-mail: ivahnov-tema@yandex.ru

${ }^{2}$ Institute of Ecological Problems of the North, Ural Branch of RAS, Arkhangelsk, Northern Dvina Emb., 23, 163002

(Russia)

${ }^{3}$ JSC «Arkhangelsk Distillery», Northern Dvina Emb., 120, Arkhangelsk, 163001 (Russia)

Comparative researches of ways of allocation of cowberry (Vaccínium vítis-idaéa) oil with application of hexan and supercritical carbon dioxide as the solvents are executed. The main indicators of quality of received oil and its fat acid content are defined. It is shown that supercritical carbon dioxide can be used for extraction of cowberry oil instead of hydrocarbons traditionally used for these purposes.

Keywords: oil, cowberry, supercritical fluid extraction, carbon dioxide, structure.

\section{References}

1. Gruppa kompanii GORO. Sverkhkriticheskaia fliuidnaia ekstraktsiia. [Group GORO. Supercritical fluid extraction.]. URL: http://www.extract.ru/. (in Russ.).

2. Thobani M., Diosady L.L. Journal American Oil Chemist's Society, 1997, vol. 70, pp. 207-214.

3. Illés V., Daood H.G., Perneczki L.S., Szokonya L., Then M. The Journal of Supercritical Fluids, 2000, vol. 17, pp. 177-186.

4. Hegel P.E., Zabaloy M.S., Mabe G.D.B., Pereda S., Brignole E.A. The Journal of Supercritical Fluids, 2007, vol. 42, pp. 318-324.

5. Hamdan S., Daood H.G., Toth-Markus M., Illés V. The Journal of Supercritical Fluids, 2008, vol. 44, pp. 25-30.

6. Freitas L.S., Oliveira J.V., Dariva C., Jacques R.A., Caramão E.B. Journal of Agricultural and Food Chemistry, 2008, vol. 56, pp. 2558-2564.

7. Corso M.P., Fagundes-Klein M.R., Silva E.A., Cardozo-Filho L., Santos J.N., Freitas L.S., Dariva C. The Journal of Supercritical Fluids, 2010, vol. 52, pp. 56-61.

8. Boutin O., Badens E. Journal of Food Engineering, 2009, vol. 92, pp. 396-402.

9. Artiunian N.S., Kornena E.P., Martovshchuk E.V. Laboratornyi praktikum po khimii zhirov. [Laboratory workshop on the chemistry of fats]. St. Petersburg, 2004, 264 p. (in Russ.).

10. GOST 13496.15-97. Korma, kombikorma, kombikormovoe syr'e. Metody opredeleniia soderzhaniia syrogo zhira. [State standard 13496.15-97. Feed, mixed feeds and raw materials. Methods for determination of crude fat]. (in Russ.).

11. GOST 30418-96. Masla rastitel'nye. Metod opredeleniia zhirnokislotnogo sostava. [State standard 30418-96. Vegetable oils. Method for determination of fatty acid composition.]. (in Russ.).

12. Gupta Ram B., Jae-Jin Shim. Solubility in supercritical carbon dioxide. New York, 2007. 909 p.

13. Tiutiunnikov B.N. Khimiia zhirov. [Chemistry of fats]. Moscow, 1974, 260 p. (in Russ.).

\footnotetext{
* Corresponding author.
} 
